\title{
Hydrogen production by photocatalysis method of glutamic acid and activated carbon
}

\author{
Yepy Komaril Sofi' ${ }^{1}{ }^{*}$, Eko Siswanto ${ }^{1}$, Winarto $^{1}$, and I Nyoman Gede Wardana ${ }^{1}$ \\ ${ }^{1}$ Department of Mechanical Engineering Brawijaya University, M.T Haryono street No. 167, Malang 65145, Indonesia
}

\begin{abstract}
This research is purposed to produces hydrogen gas as an alternative fuels by environmentally friendly photo catalysis method. The photo catalyst was made of glutamic acid $\left(\mathrm{C}_{5} \mathrm{H}_{9} \mathrm{NO}_{4}\right)$ and activated carbon both are dissolved in water in closed glass tube. In addition, halogen lamp with wavelength of 560 $\mathrm{nm}-580 \mathrm{~nm}$ was used as the lighting source. The heat from halogen lamp makes an electron orbit in the catalyst to be elliptical and polar. The photon from halogen lamp makes the electron leaps from its orbit. While the defective graphene on activated carbon gets energy from heat and photon, they will generate a magnetic field. This magnetic field energizes electron spin in glutamic acid and water while the active force in the defect of the carbon attracts the carbon atom in glutamic acid that makes it becomes more active. As a result hydrogen is produced from water. Hydrogen gas produced by the system was measured by MQ- 8 sensor inside the reactor tube. The sensor was connected to microcontroller and recorded into computer memory with Arduino Uno Software. Photo catalysis process was tested for 20 minutes. The result shows that the highest hydrogen production occurs at glutamic acid solution with $225 \mathrm{ppm}$ activated carbon.
\end{abstract}

\section{Introduction}

Fossil energy raises many environmental problems. The most serious problem is the carbon dioxide increased in the atmosphere. Recently, one of the most practical forms of energy is hydrogen. Hydrogen has attracted intensive interest as an energy source that promising and sustainable to replace fossil energy as the resource in the future [1]. Our research provides scientific information about the production of hydrogen by photocatalytic method. Catalyst that used is coconut shell activated carbon combined with glutamic acid.

Ikaeda et al [2], observed the production of hydrogen gas from water-methanol mixing in contact with photo catalyst, mixture of titanium dioxide suspension $\left(\mathrm{TiO}_{2}\right)$ and graphite silica (GS) powder. Drastic synergy effect to produces hydrogen is found for cooperated between GS and $\mathrm{TiO}_{2}$. Hydrogen gas total evolve from watermethanol mixture increased with ca.100 factor by only mixing GS with $\mathrm{TiO}_{2}$. Synergy effect associated with sifting hydrogen ion on clay component of GS and particle aggregation of GS and $\mathrm{TiO}_{2}$.

Moones et al [3] were synthesizing mesoporous $\mathrm{TiO}_{2} / \mathrm{AC}, \mathrm{Pt} / \mathrm{TiO}_{2}$ and $\mathrm{Pt} / \mathrm{TiO} 2 / \mathrm{AC}(\mathrm{AC}=$ activated carbon) nanocomposites by acid treatment and sol-gel method. Activated carbon and Pt improve simultanously hydrogen production via water splitting. Hydrogen production using $\mathrm{Pt} / \mathrm{TiO}_{2} / \mathrm{AC}$ was $7490 \mu \mathrm{mol}$ in three hours.

Pei Wen Chen et al [4] used cobalt-doped graphitic carbon nitride $(\mathrm{Co}-\mathrm{CN})$ as photocatalyst. Hydrogen rate of Co-CN exhibited $28.0 \mu \mathrm{mol} \mathrm{h}{ }^{-} 1$ under visible light irradiation. This is about 3.0 times of that over the pure $\mathrm{CN}$.

Xiaohan An et al [5] uses graphitic carbon/carbon nitride hybrid as photocatalyst. This photocatalyst has conjugation effect between carbon nitride and graphitic carbon. The result leads to a better efficiency for hydrogen production.

Shixiong Min et al [6] report that separately decorating $\mathrm{TiO}_{2}(\mathrm{P} 25)$ nanoparticles and $\mathrm{CoO}_{\mathrm{x}}$ cocatalyst on a single reduced graphene oxide ( $\mathrm{rGO}$ ) sheet results in an advanced photocatalyst, P25-rGO-Co, which exhibits enhanced photo-catalytic performances for selective $\mathrm{H}_{2}$ or $\mathrm{O}_{2}$ evolution from water splitting. Characterization results show that rGO can not only efficiently accept and transport photo-generated electrons but also shuttle holes to $\mathrm{CoO} x$ cocatalyst simultaneously, achieving an efficient spatial charge separation on $\mathrm{P} 25-\mathrm{rGO}-\mathrm{Co}$, thus improving the halfreaction efficiency.

Tatsat Banerjee et al [7] report a facile and efficient approach to facilitate photocatalytic water splitting under visible light, in single step. $\mathrm{Cu}_{2} \mathrm{O}$ was modified with $\mathrm{RuO}_{2}$ nanoparticles and used it as photocatalyst. They observed that it has a possibility of near stoichiometric overall water decomposition under visible light with appreciable quantum efficiency.

$\mathrm{NaTaO}_{3}$ photo catalyst has relatively wide energy band gap $4.0 \mathrm{eV}$ and $\lambda<310 \mathrm{~nm}$. Consequently, photocatalytic reaction could be performed by UV only [8]. The reaction cannot active under the visible light.

Corresponding author: yepykomarils@gmail.com 
Therefore, it is necessary to provide more UV light to support the evolution of hydrogen photocatalytic activity. Unfortunately, ultraviolet light only contributes less activity than $5 \%$ of sunlight so that the level of utilization of solar energy becomes very low. To get a high solar energy utilization, it must be tested using visible light $(\sim 48 \%)$ and infrared light $(\sim 44 \%)$ in sunlight.

Others studies on hydrogen production using photocatalysis method such as in Lin \& Shih [9] have used $\mathrm{Cr}, \mathrm{Ni}, \mathrm{Cu}, \mathrm{Nb}$ and $\mathrm{TiO}^{2}$ co-doped to produce hydrogen with hydrothermal photocatalyst. The catalyst was characterized by X-ray diffraction powder (XRD), Transmission Electron Microscopy (TEM), photoelectric spectroscopic analysis X-ray (XPS), $\mathrm{N}_{2}$ absorption and UV-visible spectroscopic. Photocatalytic air separation was investigated under UV light and irradiation visible light. The rate of $\mathrm{H}_{2}$ evolution significantly changes with different atoms flowing and doping concentration. Catalyst $\mathrm{TiO}_{2}$ co-doped $\mathrm{Cu} / \mathrm{N}$ was prepared by hydrothermal with $27.4 \mu \mathrm{mol} \mathrm{g}^{-1}$ hour $^{-1}$ under the UV light irradiation. The latest study have exhibited graphene effectivity as protective layer, transparent electrode, and catalyst because mechanical properties, thermal, optical, and its amazing electrical [10-12].

In our study, the photocatalyst was made of coconut shell and glutamic acid. Coconut shell contains 80.13\% of carbon. Activated carbon on coconut shell completely has composition of $80.13 \% \mathrm{C} ; 2.36 \% \mathrm{H} ; 1.1 \% \mathrm{~N} ; 0.06 \%$ $\mathrm{S}$ and $16.35 \% \mathrm{O}$ [13]. Electro catalysis experiment exhibits electron transfer that is very efficient on nanosheet Coconut Shell Carbon. This performance is caused the presence of nano pores $(<4 \mathrm{~nm})$ and the functional groups which contain much oxygen as cargo capture trap [14]. On the other hand, glutamic acid $\left(\mathrm{C}_{5} \mathrm{H}_{9} \mathrm{NO}_{4}\right)$ contains amino acid that is polar molecule having low isoelectric point, which means it easily to catch electron. Glutamic acid can be produces by human's body therefore it is not classified as essentials [15].

The photocatalyst of this research combines the photochemical reaction between light and a semiconductor catalyst in the form of graphene from activated carbon. Defective graphene on activated carbon has an ability to absorbs photon energy therefore has the ability to trigger reactions faster. The novelty of this research is the use of glutamic acid solution and activated carbon as a hydrogen-producing material by the photocatalytic method. Activated carbon is produced from coconut shell with high absorption. Activated carbon consists of graphene sheets which lose some aromatic rings in the pores locations. This defective graphene has a unique characteristic, i.e., they can repair their structure to complete the loss of aromatic ring carbon chain by attracting carbon atoms from the surrounding hydrocarbon compound. This attracting force makes Glutamic acid which is polar hydrocarbon compound easier to releases electron. The ability of the defective graphene to attract carbon atoms increases with the energy supply from photons.

\section{Materials and Method}

\subsection{Materials Preparation}

This research uses glutamic acid as hydrocarbon compound, activated carbon as semiconductor catalyst which induces glutamic acid, and water as solvent.
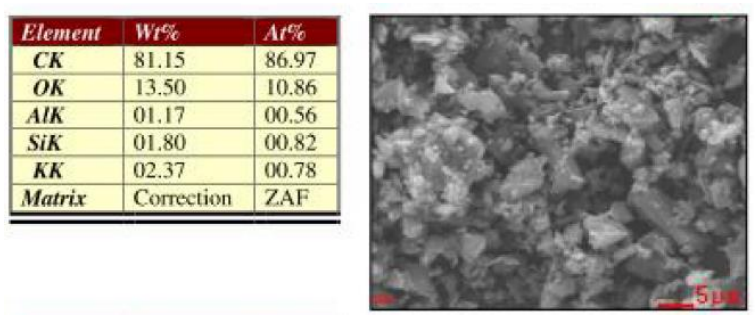

Fig. 1. SEM EDX of Activated Carbon

Fig. 1 (a) shows SEM-EDX test results. It can be seen that activated carbon from coconut shell consists of around $90 \%$ carbon $(\mathrm{C})$ and $9 \%$ oxygen $(\mathrm{O})$. The other component, silica $(\mathrm{Si})$, potassium $(\mathrm{K})$, and aluminum $(\mathrm{Al})$ are very small

Table 1. Chemical characteristic of glutamic acid

\begin{tabular}{|c|c|}
\hline \multicolumn{2}{|c|}{ Glutamic Acid } \\
\hline Chemical Formula & $\mathrm{C}_{5} \mathrm{H}_{9} \mathrm{NO}_{4}$ \\
\hline Molecular Mass & $147.13 \mathrm{~g} \mathrm{~mol}^{-1}$ \\
\hline Melting Point & $247-249^{\circ} \mathrm{C}$ \\
\hline Density & $1.538 \mathrm{~g} \mathrm{~cm}^{-3}$ \\
\hline Isoelectric point & 3.22 \\
\hline
\end{tabular}

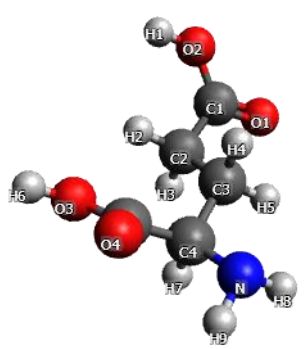

Fig. 2. The molecular structure of glutamic acid.

\subsection{Material Measurement}

The hydrogen production was measured using a MQ8 gas sensor with specification as shown in Fig. 3 and Table 2 .
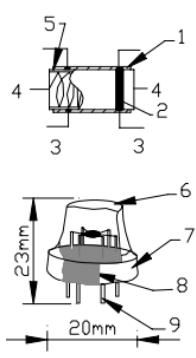

Fig. 3. Structure of MQ-8 sensor. 
Table 2. Specifications of M Q - 8 sensor.

\begin{tabular}{|c|c|c|}
\hline No. & Parts & Material \\
\hline 1 & Gas sensing layer & $\mathrm{SnO}_{2}$ \\
\hline 2 & Electrode & $\mathrm{Au}$ \\
\hline 3 & Electrode line & $\mathrm{Pt}$ \\
\hline 4 & Heater coil & $\mathrm{Ni}-\mathrm{Cr}$ alloy \\
\hline 5 & Tubular ceramic & $\mathrm{Al}_{2} \mathrm{O}_{3}$ \\
\hline 6 & Anti-explosion & Stainless steel gauze (SUS316 \\
& network & 100 -mesh) \\
\hline 7 & Clamp ring & Copper plating Ni \\
\hline 8 & Resin base & Bakelite \\
\hline 9 & Tube Pin & Copper plating Ni \\
\hline
\end{tabular}

The structure of MQ-8 hydrogen gas sensor is presented in Fig. 4 and the experimental apparatus installation is shown in Fig. 5. As shown in Fig. 4, MQ-8 gas sensor (1) which has been calibrated was placed in transparent glass tube reactor (2). The sensor was connected via connector (3) to microcontroller (4) and recorded into computer memory (6) with Arduino Uno Software via connector (5). Photo catalysis process was tested for 20 minutes. The hydrogen production recorded in ppm by the MQ-8 sensor was converted into $\mu \mathrm{mol} \mathrm{g}^{-1}$.

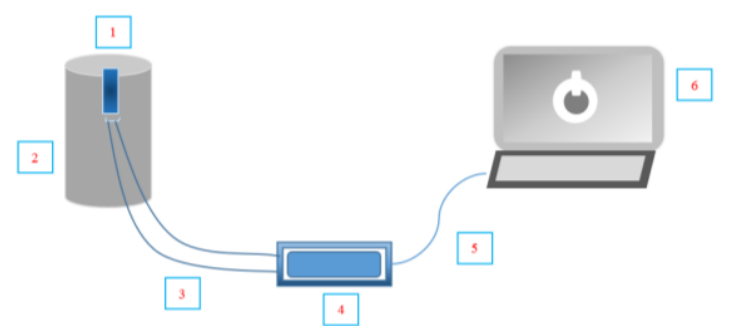

Fig. 4. Experimental Apparatus. 1. MQ-8 gas sensor; 2. Transparent glass tube reactor; 3. Connector; 4. Microcontroller; 5. Connector; 6. Computer.

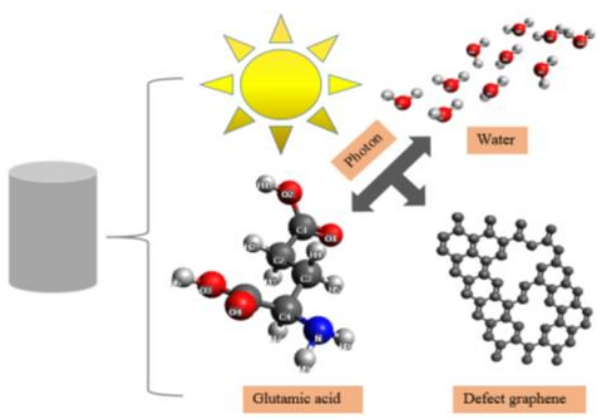

Fig. 5. Reaction which occurred in the transparent glass tube reactor.

Fig. 5 shows the concept of reaction which occurred in the transparent glass tube reactor by glutamic acid and activated carbon assisted water photocatalysis. In this composition activated carbon acts as internal magnet and glutamic acid as polar compound. As the defective graphene on activated carbon gets photon, they will generate a magnetic field. This magnetic field energizes electron in glutamic acid and water while the active force in the defect of the activated carbon attract the carbon atom in glutamic acid that makes it becomes more active as illustrated in more detail in Fig. 6.

\section{Results and Discussion}

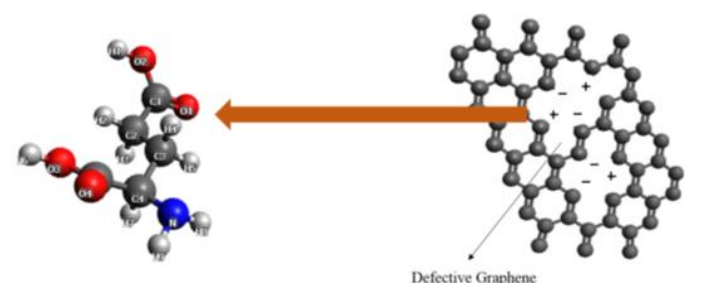

Fig 6. Defective graphene induces carbon bond of glutamic acid.

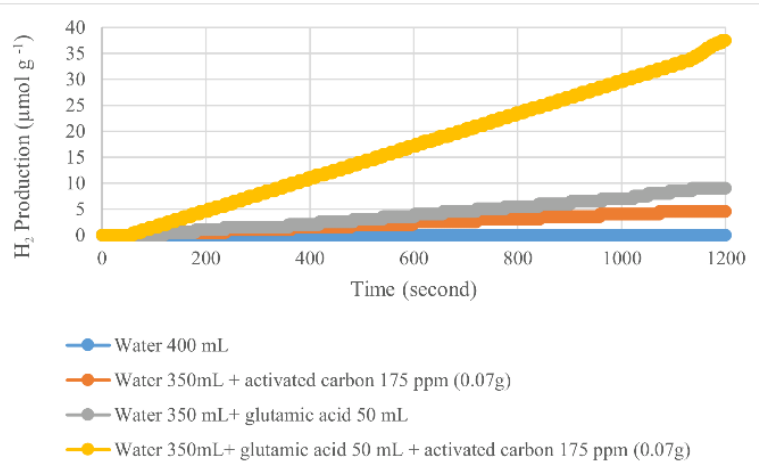

Fig. 7. Hydrogen production from photocatalytic process.

Fig. 7 shows hydrogen gas which is produced by photo catalysis, glutamic acid solution and activated carbon. Water which is consisted from hydrogen bonds requires a lot of energy to break this bond. Therefore, water without photo catalysis cannot produce hydrogen. As a result, hydrogen bonds in water have not been decomposed. When water was added with glutamic acid or with activated carbon or with both glutamic acid and activated carbon, the hydrogen gas can be produced. With activated carbon of $0.07 \mathrm{~g}$ only, the hydrogen gas obtained is $4.5 \mu \mathrm{mol} \mathrm{g}^{-1}$ in 20 minutes. With glutamic acid of $50 \mathrm{~mL}$ only, the hydrogen production is higher, i.e., $9 \mu \mathrm{mol} \mathrm{g}^{-1}$ in 20 minutes. This shows that when the defective graphene on activated carbon gets heat energy and photon, they will generate a magnetic field while active side in the defect attracts water molecules. This magnetic field energizes electron in water which together with attractive force from the defect weakens hydrogen bonds and decomposes water into hydrogen. On the other hand, glutamic acid is a polar compound. As the glutamic acid gets heat energy and photon, they will generate a temporary dipole. This dipole force also weakens hydrogen bond on water and decomposes water into hydrogen. The higher hydrogen production from water with glutamic acid is mainly due to its higher ppm concentration. The highest photocatalysis effect occurred on water with glutamic acid of $50 \mathrm{~mL}$ and activated carbon $0.07 \mathrm{~g}$ which produce hydrogen gas of $37.5 \mu \mathrm{mol}$ $\mathrm{g}^{-1}$ in 20 minutes, much higher than those in activated carbon only or in glutamic acid only. In this composition activated carbon acts as internal magnet and glutamic acid as polar compound. As shown on Fig. 6 while the defective graphene on activated carbon gets heat energy and photon, they will generate a magnetic field. This magnetic field induces electron in glutamic acid and water while the active force in the defect of the activated 
carbon attract the carbon atom in glutamic acid that makes it becomes more active. This interacting force between activated carbon and glutamic acid is the reason of the highest increase in hydrogen production.

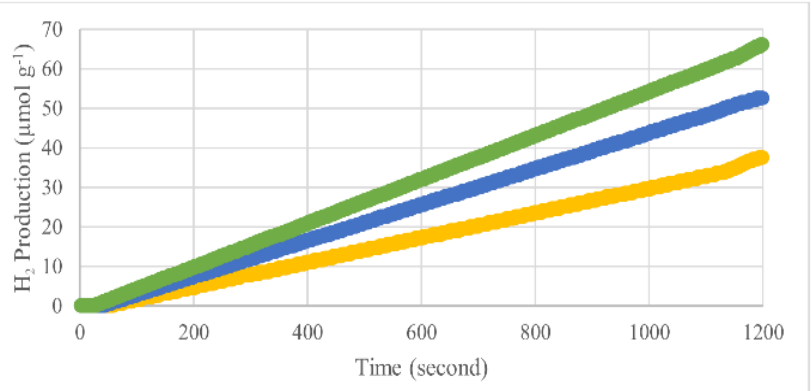

$\rightarrow$ Water $350 \mathrm{~mL}+$ glutamic acid $50 \mathrm{~mL}+$ activated carbon $175 \mathrm{ppm}(0.07 \mathrm{~g})$

$\rightarrow$ Water $350 \mathrm{~mL}+$ glutamic acid $50 \mathrm{~mL}+$ activated carbon $200 \mathrm{ppm}(0.08 \mathrm{~g})$

$\longrightarrow$-Water $350 \mathrm{~mL}+$ glutamic acid $50 \mathrm{~mL}+$ activated carbon $225 \mathrm{ppm}(0.09 \mathrm{~g})$

Fig. 8. Hydrogen production at various activated carbon.

Fig. 8 shows the hydrogen gas production that is enhanced as the amount of activated carbon increase. Activated carbon which consisted from graphene defect sheets have a unique characteristic, they can repair themself by attracting carbon from other compound. Photon and heat of photocatalysis increase the electron delocalization on graphene. It generate magnetic field significantly. In this research defective graphene attracts carbon from glutamic acid $\left(\mathrm{C}_{5} \mathrm{H}_{9} \mathrm{NO}_{4}\right)$. This interacting force can produce large amount of hydrogen.

The mechanism of defected graphene in activated carbon attract carbon atom from glutamic acid under the effect of photon from halogen lamp is shown in Fig. 9. The photon from halogen lamp light with wavelength $560 \mathrm{~nm}-580 \mathrm{~nm}$ makes electron on activated carbon that excited from valence band into conduction band. On conduction band the reduction takes place that produces oxygen $\left(\mathrm{O}_{2}\right)$. On valence band, the oxidation produces radical: $\mathrm{OH}^{-}$and $\mathrm{H}^{+}$. As shown in Fig. 9, activated carbon is consisted from defective graphene which can repair the defect by attracting carbon from glutamic acid. Graphene is a hexagonal aromatic ring. It will absorb energy when photon illuminated. Therefore delocalization electron can be more active. It generate magnetic field that induces electron in glutamic acid.

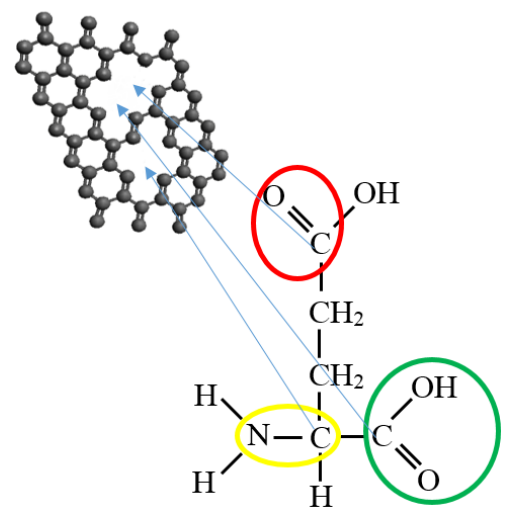

Fig. 9. Defective graphene attracting carbon from glutamic acid
It is important to note that based on Pauli theory, electron in weak magnetic field will be attracted into stronger magnetic field. The electrostatic force is smaller than the electromagnetic force. Therefore carbon bond in glutamic acid become weak and decomposed. Based on kinetic theory where the speed of an electron is directly proportional to the increase of temperature. Nonpolar carbon on glutamic acid will be induced into polar molecule. Synergy occurs between the role of photons and heat in photo catalysis.

Water is consisted of covalent bond and hydrogen bond. Defective graphene induces hydrogen bond since it is weaker than covalent bond. The decomposition of hydrogen bond can be proven with Brownian motion in water. The bond becomes polyatomic anion $\left(\mathrm{OH}^{-}\right)$and monatomic cation $\left(\mathrm{H}^{+}\right)$. To fulfill the octet rule, the anions and cations will react with other atoms to be stable. $\mathrm{H}^{+}$join with other $\mathrm{H}^{+}$become $\mathrm{H}_{2}$ and $\mathrm{O}^{2-}$ join with $\mathrm{O}^{2-}$ become $\mathrm{O}^{2}$.

In Moones et al [3] which use $\mathrm{Pt} / \mathrm{TiO}_{2} /$ Activated Carbon(AC) photo catalyst in an aqueous solution of methanol under UV light irradiation obtained the maximum $\mathrm{H}_{2}$ production of approximately $7490 \mu \mathrm{mol}$ (g catal $)^{-1}$ in three hours at $\mathrm{Pt}$ content of $0.75 \mathrm{wt} \%$. Further increasing of the Pt loading decreases the amount of $\mathrm{H}_{2}$ production. The average rate of the $\mathrm{H}_{2}$ gas produced using $\mathrm{Pt} / \mathrm{TiO}_{2} / \mathrm{AC}$ catalyst is about 20 times higher than that of the $\mathrm{TiO}_{2} / \mathrm{AC}$ photocatalyst and 75 times higher than that of commercial P25 photocatalyst. These results indicate that the presence of the $\mathrm{AC}$ and $\mathrm{Pt}$ impurity deposited on the $\mathrm{TiO}_{2}$ enhance the hydrogen production, significantly. In addition, Shixiong Min et al [6] reported that highest hydrogen evolution was around $700 \mu \mathrm{mol} \mathrm{g}^{-1}$ with P25-rGO-co photocatalyst. This result was obtained for 4 hours photocatalysis.

In Xiaohan An research [5] the hydrogen evolution increased steadily with irradiation time in both the graphitic carbon/carbon nitride hybrid CMA and MA. Obviously, the MA samples remarkably increased the photocatalytic activity in $\mathrm{H}_{2}$ evolution as compared with MA. During 8 hours of reaction, the cumulative production of $\mathrm{H}_{2}$ over the CMA reached to $3800 \mu \mathrm{mol} \mathrm{g}$

${ }^{-1}$, which was twice as much as that of MA. The carbon hybrid was contributed to enhance the photocatalytic activity because the carbon hybrid accelerated charge mobility and prolonged electron lifetime in the CMA sample, as indicated by the photochemical properties.

The hydrogen production in this study as shown on Fig. 8 reached to $792 \mu \mathrm{mol} \mathrm{g} \mathrm{g}^{-1}$ during 4 hours photocatalysis for water with glutamic acid of $50 \mathrm{~mL}$ and activated carbon of $0.09 \mathrm{~g}$ composition. This result is the same as that in Shixiong Min et al [6]. In fact, the increase of activated carbon has a significant effect on hydogen production. Activated carbon and glutamic acid have an important and significant part on photo catalysis for they create interaction force effect under the heat and photon irradiation. 


\section{Conclusions}

Activated carbon and glutamic acid assisted water photocatalyst to produces hydrogen gas as an alternative fuels by environmentally friendly. Activated carbon acts as internal magnet and glutamic acid as polar compound. As the defective graphene on activated carbon gets photon, they will generate a magnetic field. This magnetic field induces electron in glutamic acid and water while the active force in the defect of the carbon attract the carbon atom in glutamic acid that makes it becomes more active. This interaction force effect creates by the defect in the graphene on the activated carbon becomes the key factor that amplify the hydrogen production in photocatalysis system.

The work is financially supported by master of education scholarship towards doctorate for outstanding bachelor (PMDSU), directorate general of science and technology resources, ministry of research, technology, and higher education Republic of Indonesia.

\section{References}

[1] Bae. H, Rho. H, Min, J. H, Lee, Y. T, Ha, J. S, Applied Surface Science. 422, 354-358 (2017)

[2] M. Ikeda, Y. Kusumoto, S. Somekawa, P. Ngweniform, B. Ahmmad, J. Photochem.Photobiol A. 184, 306-312 (2006)

[3] Hakamizadeh. M, Afshar. S, Tadjarodi. A, Khajavian. R, Fadaie. M. R, Bozorgi. B, International Journal of Hydrogen energy. 39(14), 7262-7269 (2014)

[4] Chen. P. W, Li. K, Yu. Y. X, Zhang. W. D, Applied Surface Science. 392, 608-615 (2017)
[5] An. X, CaO. Y, Liu. Q, Chen. L, Lin. Z, Zhou. Y, Wang. X, Applied Catalysis A: General. 546, 30-35 (2017)

[6] Min. S, Wang. F, Lu. G, Catalysis Communications. 80, 28-32 (2016)

[7] Banerjee. T, Mukherjee. A, Energy Procedia. 54, 221-227 (2014)

[8] Jirapat. A, Puangrat. K, Supapan. S, J Hazard Mater. 168(1), 253-61 (2009)

[9] Wang, J, Tafen, D, N, Lewis, J, P, Hong, Z, Manivannan. A, Zhi. M, J Am Chem Soc. 131(12), 290-297 (2009)

[10] Lin. H. Y, Shih. C. Y, J Mol Catal a Chem. 411, 128-37 (2016)

[11] Novoselov. K.S, Geim, Morozov. S.V, Jiang. D, Zhang. Y, Dubonos. S. V, Grigorieva. I. V, Firsov. A. A, Science. 422(306), 666-669 (2004)

[12] Zhang. Y, Zhou. C, Acc. Chem. Res. 46, 23292339 (2012)

[13] Iqbaldin. M. N. M, Khudzir. I, Azlan. M. I. M, Zaidi. A.G, Surani. B, Zubri. Z, Journal of Tropical Forest Science. 25(4), 497-503 (2013)

[14] Zha. W. D, Li. L.F, Pan. Y. X, He. J. Bo, International Journal of Hydrogen Energy. 41, 17370-17379 (2016)

[15] George. J. Siegel, Bernard. W. Agranoff, R. Wayne. Albers, Stephen. K. Fisher, Michael. D. Uhler. Mental Health Research Institute 6th ed. Lippincott-Raven. ISBN 0-397-51820-X (1999) 